\title{
Energy Management Control Algorithm Based Bidirectional DC-DC Converter for Small Scale Micro Grid with Hybrid Storage System
}

\author{
R.Rajasekaran, P.Usha Rani
}

\begin{abstract}
This work recommends a Energy management algorithm for bidirectional DC-DC Converter to Small scale micro grid, for example, wind, sun based energy resource and battery, Super capacitor. An energy management control algorithm, which can ensure that the availability of Energy at hybrid sources, based on the load power demand and the battery and Super Capacitor of energy state, which is established to operate the Small Scale micro grid as a self-sufficient mode. Control calculation and Power converters operation has been utilized alongside committed Energy Resource for the effective buck-boost operation of the Small Scale micro grid. The control calculations are produced to give control similarity and Energy management between various resources in the micro grid. The proposed control arrangement of DC-DC converter some rationale entryways are utilized to appropriately separate the battery and Super Capacitor from Direct current connect.The operation is simulated and modelled by Mat lab software.
\end{abstract}

Key Words: - Energy management Control Algorithm, Bidirectional DC-DC Converter, Battery, Super capacitor,Small scale Micro Grid, Hybrid energy resource,

\section{INTRODUCTION}

BY means of the rushed advancement of the storage of electrical charge storage innovations, Direct current control frameworks is ending up generally utilized as a part of different applications. In power association, huge electric energy storage, for example, Li-ion Batteries advance dispersed sustainable power sources, which incorporate photovoltaic power frameworks, wind generator frameworks, and energy component frameworks in smaller scale micro grid [1],[2]. These days, there are numerous subjects for future transportation investigate identified with electric charge storage frameworks and batteries, Regarding energize ability, electrical energy storage system, for example, batteries or super capacitors require bidirectional DC-DC energy change to improve structure efficiency [3],[4], As to association strategies for the energy storage device, circulated energy foundations, load at micro grid, the transportation of Direct current are the easiest connection transport. This Set up work brings about high efficiency, more dependability, and stage control prerequisites or no recurrence, when contrasted with the Ac interconnection transport [5],[6]. In addition, it is low circulation and transmission misfortunes, minimal effort, the likelihood to

Revised Manuscript Received on August 14, 2019.

R.Rajasekaran, Research scholar, Department of EEE ,Anna University, Sri Lakshmi Ammal Engineering College, Chennai, T.N, India (rajaskrn1985@gmail.com)

Dr.P.Usha Rani, Professor, Department of EEE, R.M.D Engineering College, Kavaraipettai -Chennai-601206 T.N, India (pur.eee@rmd.ac.in) work crosswise over long separations, and it doesn't utilize transformers, thus prompting volume and cost diminishment [7]. Subsequently, optimum size of bidirectional converters and its prize minimization is effectively tried to support the development of framework execution. To accomplish this objective, control power advancements are being created utilizing a few methodologies, thinking about circulated resources of various generation technique, microgrid connection frameworks would be advanced fascinating answer for non-conventional energy generation and reliable generation for home application. The micro grid under examination here, as appeared in Fig. 1 shown the Distributed Generating resources (Wind \& PV board),storage of energy structure ( super capacitor \& Battery ), and Moreover, it can stream the both Dc and Ac loads. Here small scale micro grid have two bus: first Ac bus its connecting of Ac loads are associated and the purpose of regular coupling with utilization framework has found and Second is Dc bus in which the Distribute Generation sources, dc loads and energy storage are associated,. In the small scale micro grid structures, the energy storage framework is of extraordinary significance. It is in charge of providing energy to the load when the principle sources are not fit amid brief time frames and enduring state task. The proposed private small scale micro grid energy storage framework made out of a super capacitor and battery bank has two primary capacities. Here battery act as a reinforcement method because of its great vitality thickness [8] [9], Giving power can act under the enduring state-run condition whenever alternate sources are not working. Alternative super capacitor ready to snappy release bank because of its powerful thickness [11] [12], giving energy to the smaller scale framework during momentary periods, Consequently, because of the significance of the energy storage framework, Subsequently super capacitor get not controlled and its voltage is start to decrease, the Dc- Dc converter should have a more power proportion along with information and yield stages. Additionally, it should be capacity to working for broad yield control. Its work mainly focused around Dc control technique for small scale micro grid for store energy framework.. A less number of Dc-Dc converter topologies utilizing super capacitor to supplement the backup storage 


\section{ENERGY MANAGEMENT CONTROL ALGORITHM BASED BIDIRECTIONAL DC-DC CONVERTER FOR SMALL SCALE MICRO GRID WITH HYBRID STORAGE SYSTEM}

by different resources, for example, power modules, batteries, generators, have been proposed in the writing [13]-[14]. Part of an Energy Management System (EMS) in the general Small scale micro Grid. Which is play out the power at the grid side is managed to guarantee productive power exchange from the resource and storage system to the micro grid,

\section{PROPOSED BIDIRECTIONAL CONVERTER}

The target of this project has proposed outline for Small scale standalone micro grid that uses hybrid energy resources, for example, solar energy, wind, Super capacitor and battery energy storage. The energy transferring this diverse sources are overseen utilizing management algorithm of ontrol where utilized as a part of the realtime control condition.

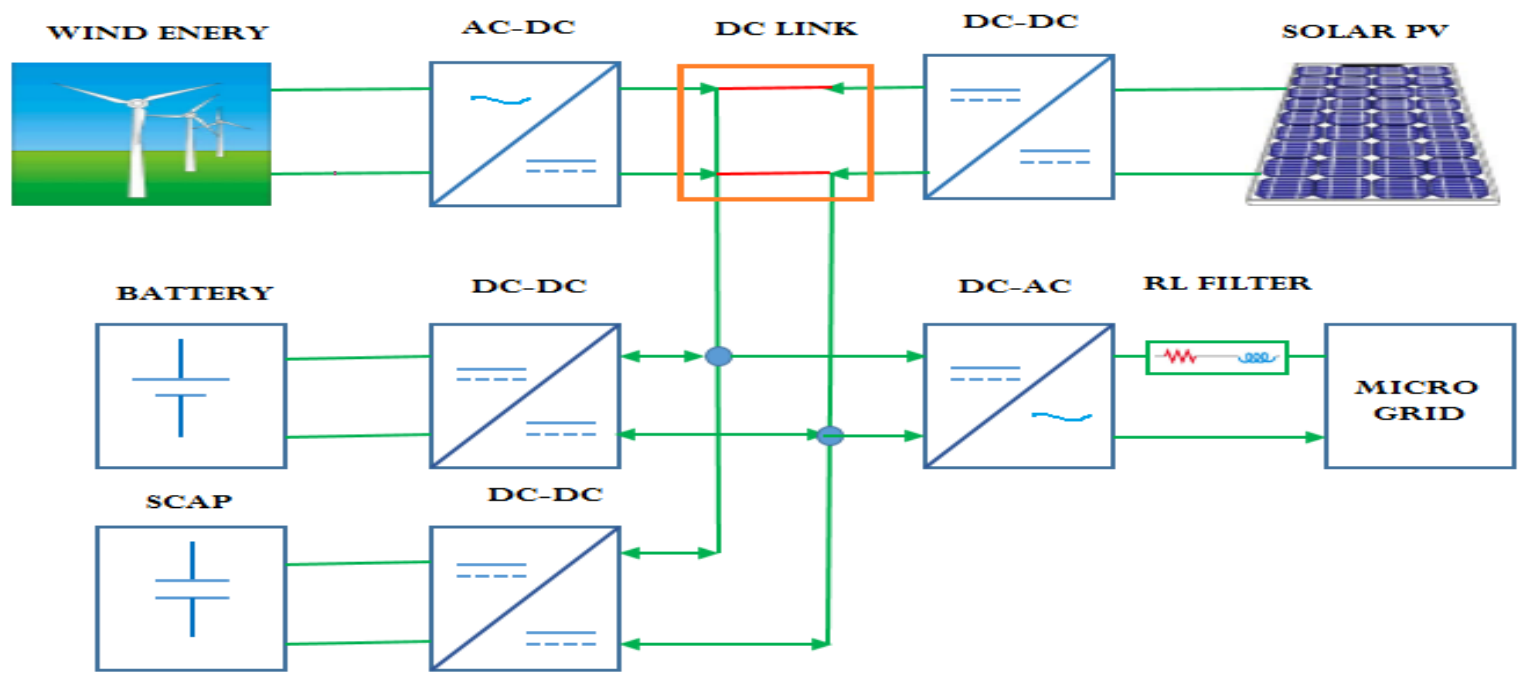

Fig.1. Block Diagram of Bidirectional DC-DC Converter

The projected structure has an open architecture structure show in fig.1 where distinctive control algorithm and electronic converter arrangements and it could be performed and attempted to surveying for grid execution. Preliminary manageable power source proving ground fuses three vital parts: - non conventional energy resource (solar photo voltaic module and wind turbine along with PSGM) with reasonable electronic converters, Super capcitor and battery based vitality stockpiling framework, and main AC load. These portions is associated via a DC-interface as showed up in Fig. 1 control of overall system operation has been explained below.

\section{TOPOLOGY AND OPERATING PRINCIPLE OF PROPOSED CONVERTER CIRCUIT}

\section{A.Topology}

The proposed small scale micro grid is worked as a smart framework by a energy management and control framework. A energy management algorithm, mulling over the accessible energy at the inexhaustible bases, micro grid control request are main condition of charge of the Super capacitor and battery, this work created a Small scale micro grid as a self-Sufficient framework. The power from micro grid will be effective guarantee of power exchange between the vitality sources to micro grid.

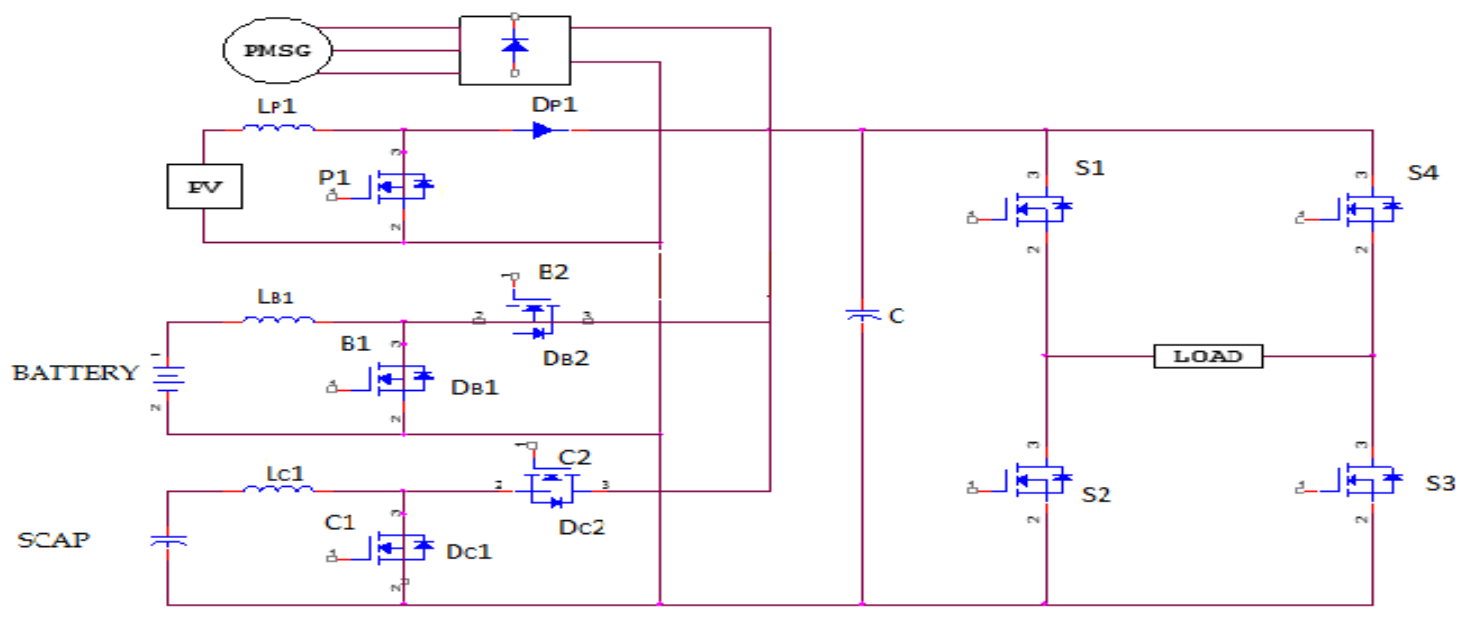

Fig.2 Topology of converter circuit 


\section{B. Converter Description}

Fig. 2 demonstration of proposed Bidirectional Dc-Dc converter, The switch S1 S2 S3 and S4 are the principle switches of the Load side. Moreover, P1, B1,B2 and $\mathrm{C} 1, \mathrm{C} 2$ are the Switches Across the photo voltaic ,Battery and Super capacitor Respectively to performs Buck Boost operation. The Switches can turn $\mathrm{ON}$ and turn OFF based on the availability of power transferred from source to Energy storage system and load.DP1, DB1 DB2 and DS1, DS2 are the switching device connected across the respective switches to perform the unidirectional current flow, LP1, LB1 and LS1 coupling inductors connected series with source and Energy storage systems.

\section{Circuit Operation}

\section{Modes of operation}

\section{Mode 1:(Battery Discharge)}

In Steady state operation load voltage is greater than the source voltage then the stored battery energy is discharging. With the help of B1, The switch B2 are Turned OFF, The current will flow from battery to load through DB2, the inductor LB1 is used for boost operation. In this condition super capacitor is in ideal.

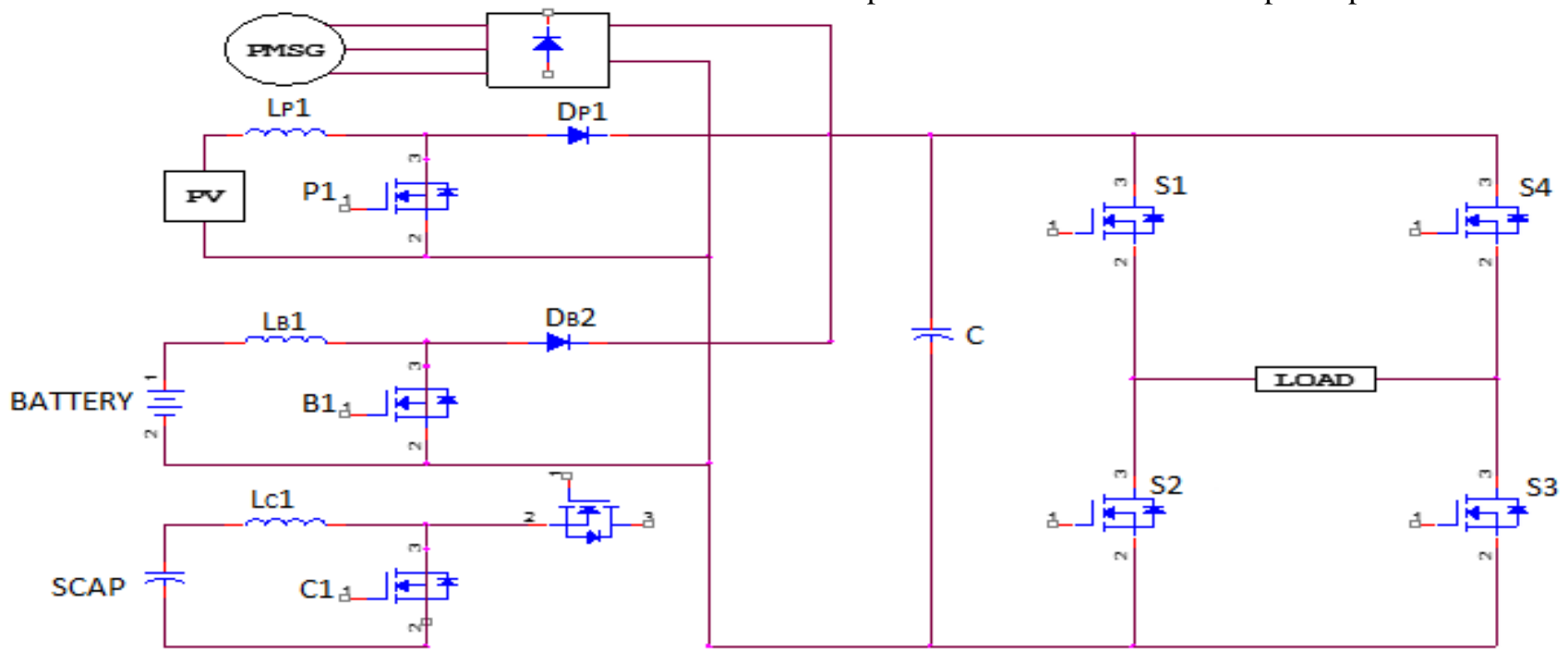

Fig.3 Battery Discharging Mode

\section{Mode 2:(Battery Charging)}

SOC of super capacitor is $100 \%$ then the source voltage is greater than the load voltage. Then the energy will be stored in the battery by the buck operation. Switch B2 is in ON condition. The Inductor LB1 will start to store and it will dissipate energy through Diode DB1,

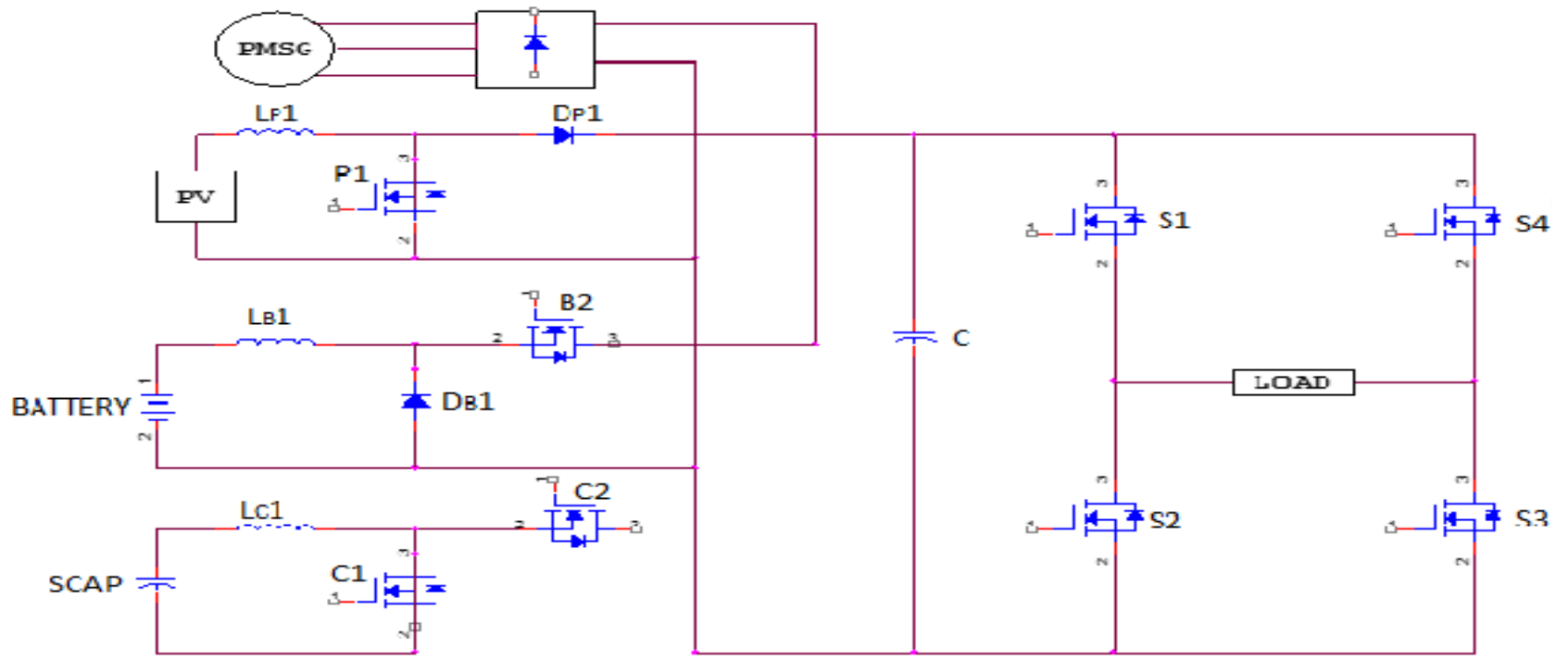

Fig.4 Battery Charging Mode 


\section{ENERGY MANAGEMENT CONTROL ALGORITHM BASED BIDIRECTIONAL DC-DC CONVERTER FOR SMALL SCALE MICRO GRID WITH HYBRID STORAGE SYSTEM}

\section{Mode 3:(Super capacitor Discharge)}

In Steady state operation load voltage is greater than the source voltage then the stored Super capacitor energy is discharging. With the help of $\mathrm{C} 1$, The switch $\mathrm{C} 2$ are
Turned OFF, The current will flow from Super capacitor to load through DC2, the inductor LC1 is used for boost operation. In this Battery is in ideal.

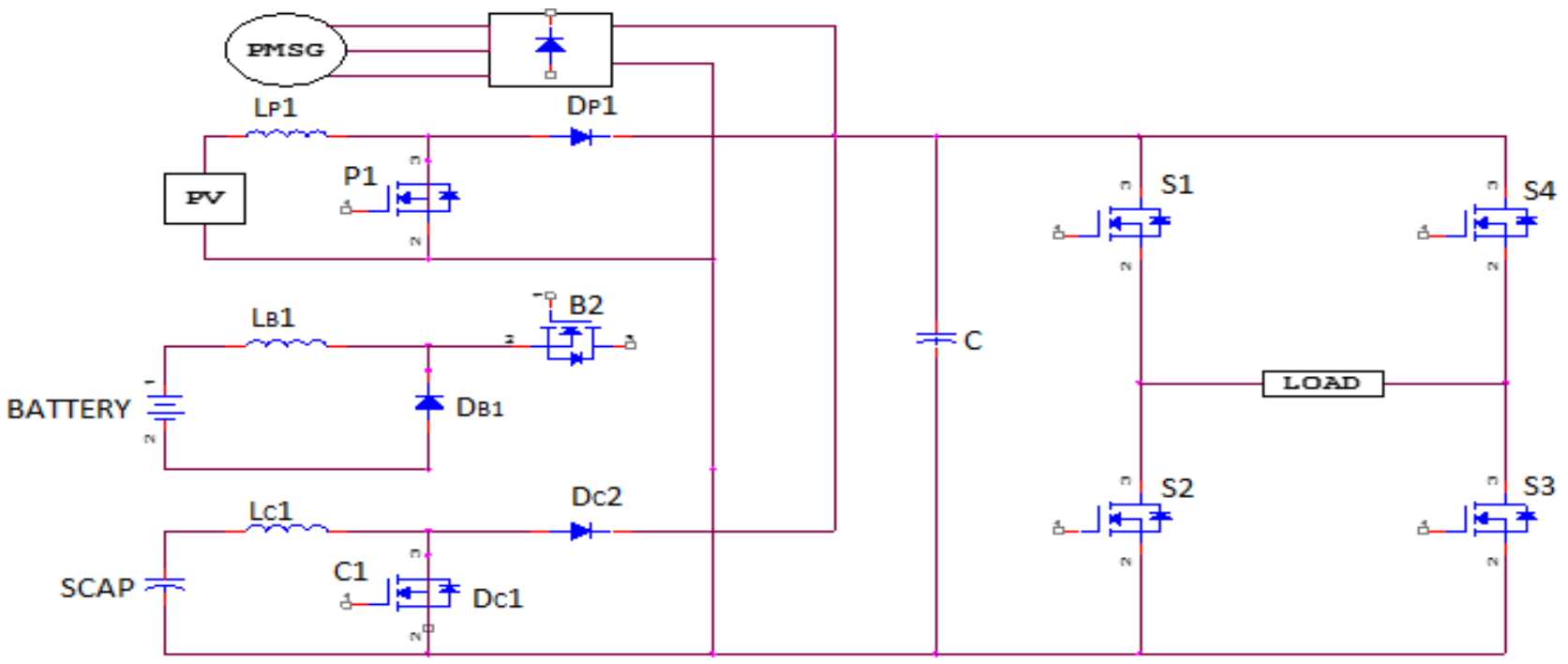

Fig.5 Super Capacitor Discharging Mode

\section{Mode 4:(Super capacitor Charge)}

SOC of Battery is $100 \%$ then the source voltage is greater than the load voltage. Then the energy will be stored in the Super capacitor by the buck operation.
Switch C2 is in ON condition. The Inductor LC1 will start to store and it will dissipate energy through Diode DC1,

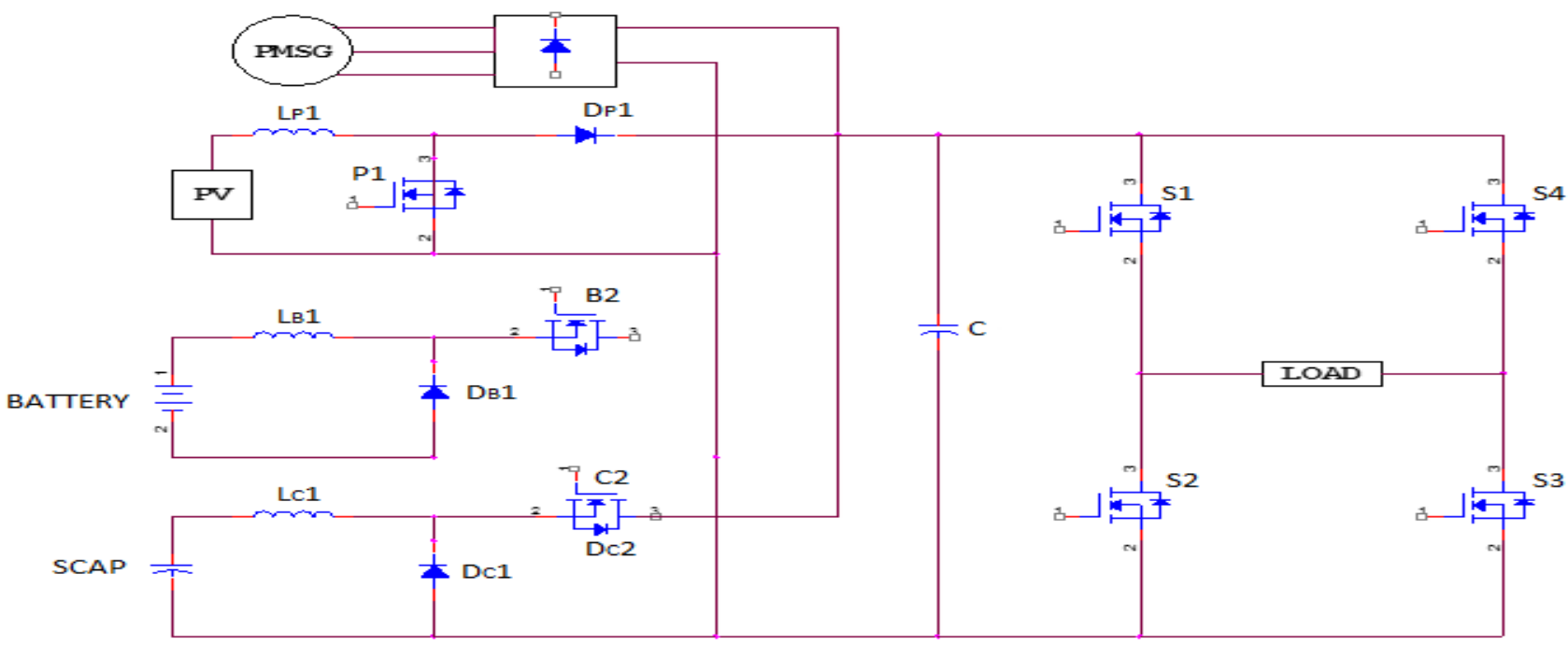

Fig.6 Super Capacitor Charging Mode

\section{HYBRID STATE OF CHARGE BANKS \& RESULTS}

The Hybrid state of charge banks (HSCB) comprises of Super capacitor, battery and a bidirectional DC-DC converter support along with Dc-connection for small scale micro grid. The piece of this converter can with stand DC-connect voltage steady in spite of the energy exchanges at sources to micro grid. All the voltage level in this converter can be controlled by HSCB via a Proportional integral controller and its course system is appeared in Fig 7.

\section{A.HSCB}

An important parameter to represent the state of the battery is the state of charge (SOC) expressed by

$$
\mathrm{SOC}=100\left[1+\left(\int \text { Ibat } d t\right) / Q\right]
$$

Where, Q is the battery volume and $I_{b a t}$ is the battery storing current

The availability of power depend on batter charging and discharging power, the need for and State of charge [1]. SOC which can ensure the limits of batter power,

State Of Charge min $\leq$ State Of Charge $\leq$ State Of Charge $\max [2]$ 
Where, State of charge are the minimum and the maximum permissible states of the battery safe

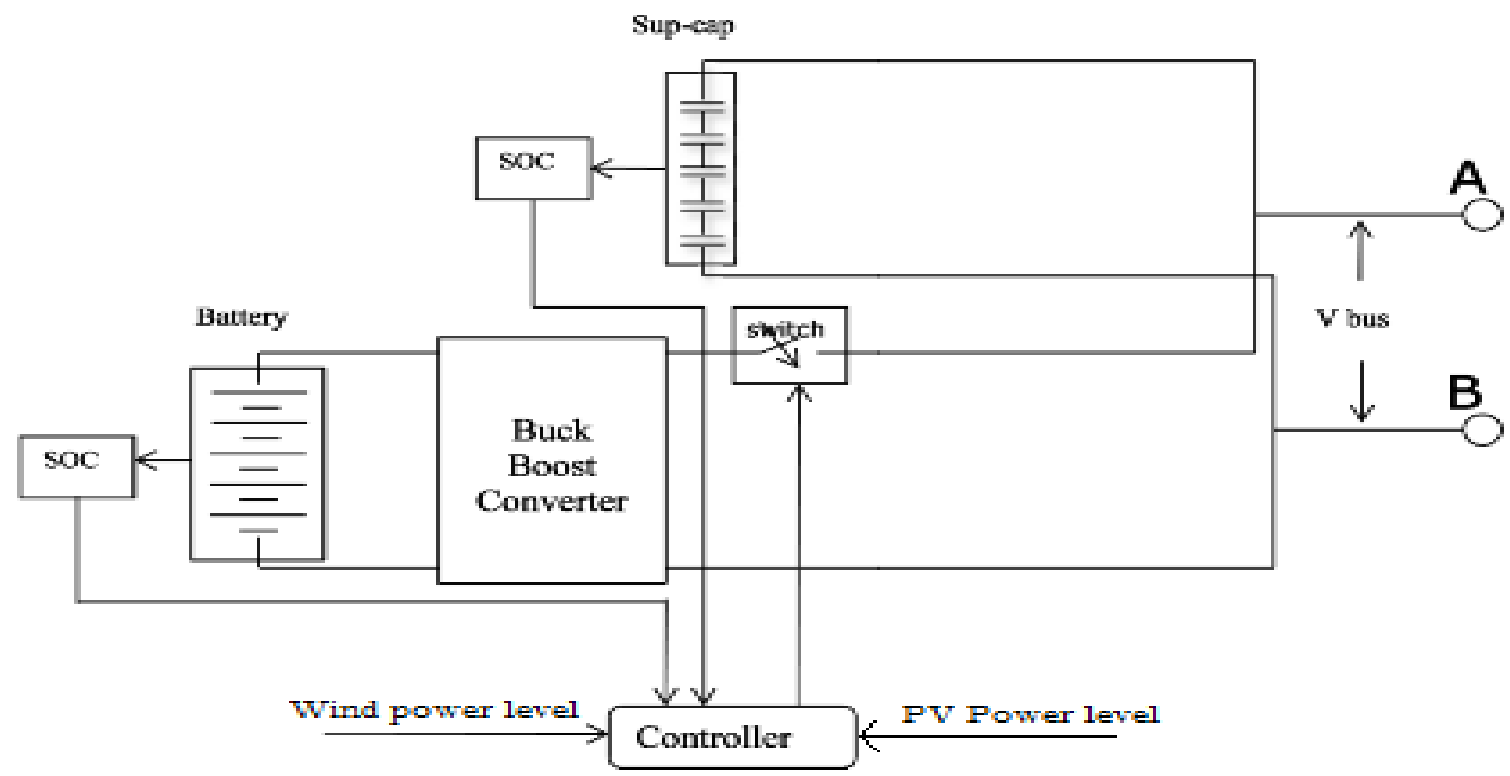

Fig.7 Model of HSCB and Control Structure

Shown the HESS prototypical and associated controller, The controller comprises the SOC of battery and Super capacitor and also wind and PV power, The controller of HSCB getting lower bond and the upper bond of Super capacitor state of charge and Battery state of charge respectively, If SOC Battery reaches low then SOC of Super capacitor start to discharge, else If SOC Battery reaches high then SOC of Super capacitor start to charge,

\section{CONTROL TECHNIQUE}

The control technique which proposed the energy management system for resource and storage to micro grid. the Dc-Dc converter of the Photo Voltaic panel and wind energy Maximum Power Point Tracking may work in the on-MPPT or off-MPPT modes in view of the framework control adjust and energy imperatives, the DcDc converter for super capacitor and battery performed both in charging or releasing type, which is based on the power regulating mode, keeping in mind the end goal which consistent of DC-connect voltage.

The power in the micro grid under various loads and supply conditions should be balanced as follows

$$
P_{P V}+P_{w}-P_{\text {loss }}=P_{L}+P_{b a t}+P_{\text {scap }}
$$

Where, $P_{b a t}$ is the battery power $P_{S C A P}$ is the super capacitor power and $P_{\text {loss }}$ is losses for small scale grid.
The Photo Voltaic converter operating mode (offMPPT ,On-MPPT,) the super capacitor and battery storage system energy flow direction are controlled by the energy management technique based on structure of total power $P$, the vitality limitations of the super capacitor and battery. The flow chart diagram is given in Fig. 8 .

On and remote possibility of power, made at endless sources (solar and wind based), are missing for the solicitation control at the heap side (Pnet), due to a potential rise in the Dc-associate voltage VDC.The +ve blunder $(\mathrm{V} * \mathrm{Dc}-\mathrm{VDC})$ generate a +ve reference of current, it would make the converter in less mode to trade control from the HSCB to the heap (Discharge) in case of its State of charge are high noticeable than the base regard, for the most part stack shedding is required to keep up control change as the power supply isn't as much as solicitation and HSCB of the base (SOC min). If there should be an occurrence of intensity age surpassing the heap control, DC-connect voltage $\mathrm{V}$ expands, it might be a control of reference current that the battery and Super capacitor converter for lift mode (charge), for that power streams from the primary DC-connection to the HSCB with the extra created power, in any case, if the HSCB state of charge surpasses its most extreme (SOC max), the HSCB energy mode off, and the Photo Voltaic framework works in off-MPPT mode to decrease the produced power so as to adjust the power in the small scale microgrid. 


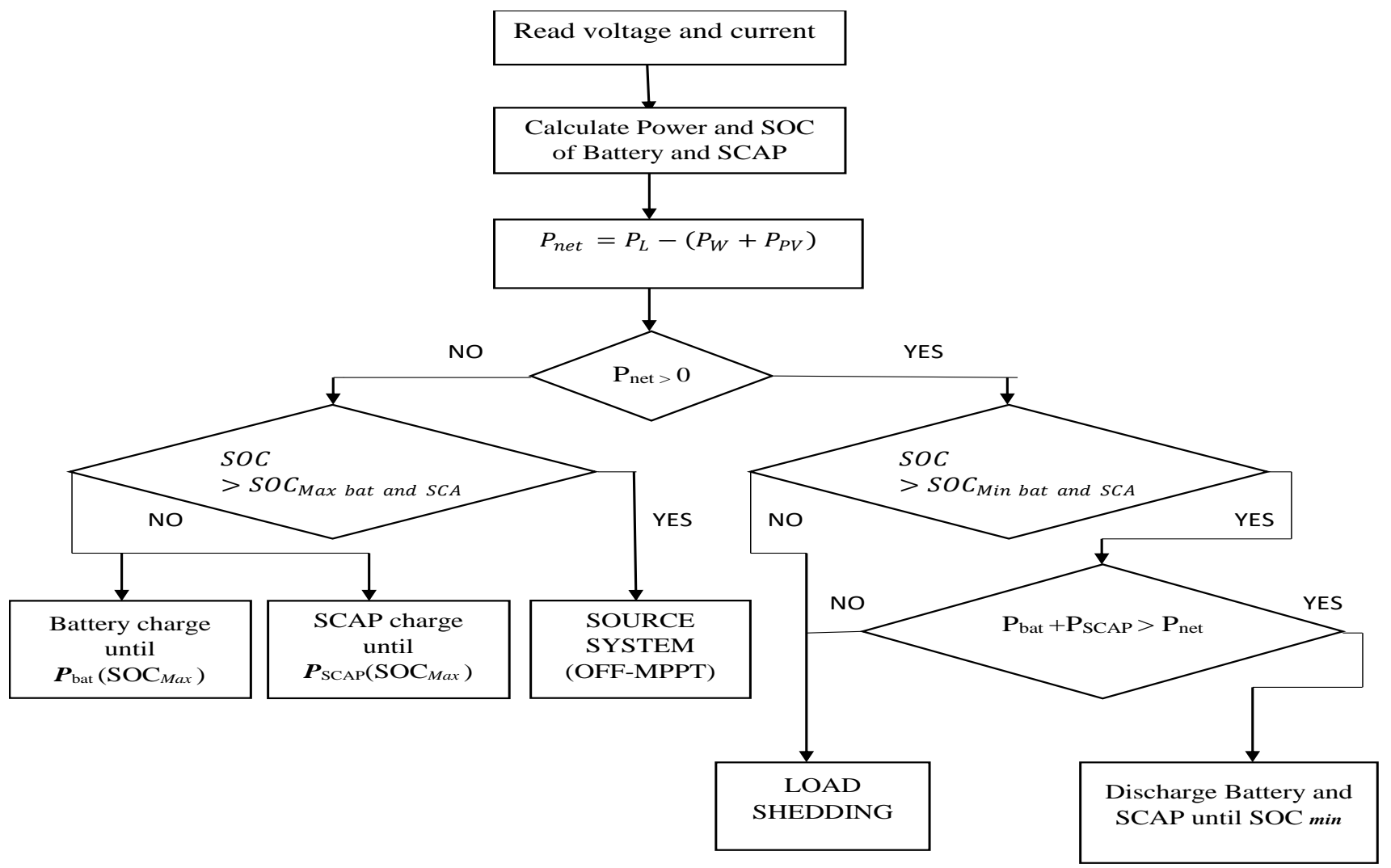

Fig.8. Energy management system flow chart

\section{CONTROL ALGORITHM}

The proposed control concept is summarized in Algorithm 1.

EMS algorithm

function [ctrl1, ctrl2, ctrl3, ctrl4] =

fcn (Ppv, Pw, PL, BAT_SOC,SCAP_SOC)

o\#codegen

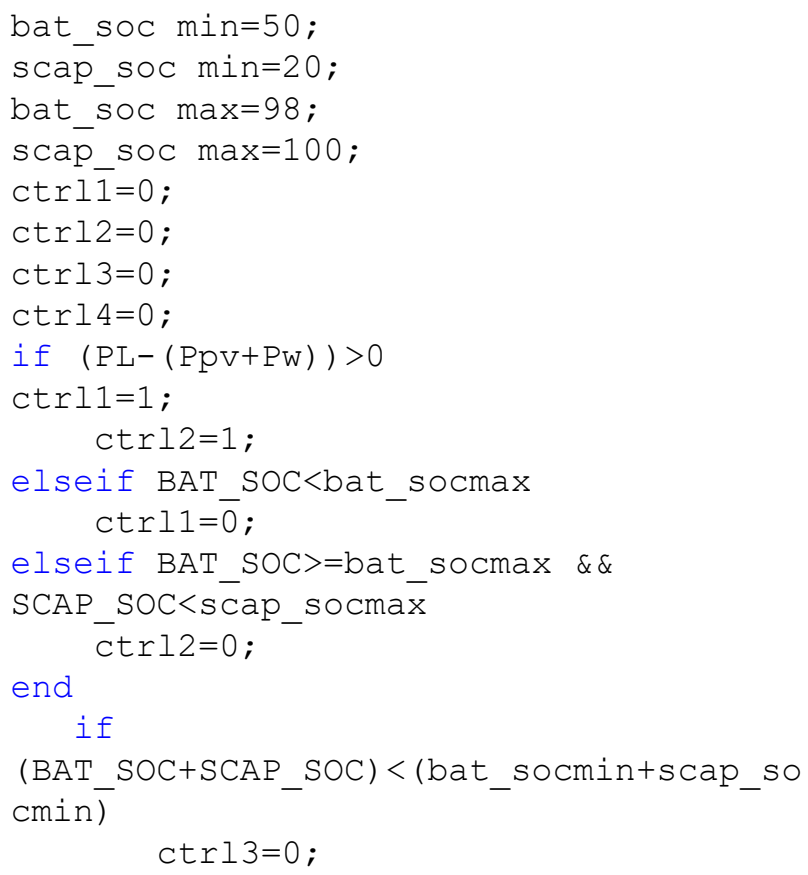

\section{SIMULATION RESULT FOR PROPOSED SYSTEM AND CONTROL SCHEME}

So as to confirm the exhibition of the model of converter, simulations have been done in all four operation modes by

Mat-lab/ Simulink software. The efficiencies, whenever energy is flow from the PV and Wind source to the Super capacitor and battery, from the Super capacitor and battery to the load, and from the PV and Wind source to the load, are analysed through the simulation Software. Here at simulink model, There are two input sources like $\mathrm{PV}$ and Wind Source voltages $\mathrm{VI}=150 \mathrm{~V}$ and V2 $=$ $200 \mathrm{~V}$, respectively. and $300 \mathrm{~V}$ as set as reference voltage.

From $\mathrm{t}=0$ to 1 load is set to $20 \mathrm{ohms}$, corresponding load power is 20 watts and from $t=1$ to 2 load is set to 1 ohms, corresponding load power is 440watts 

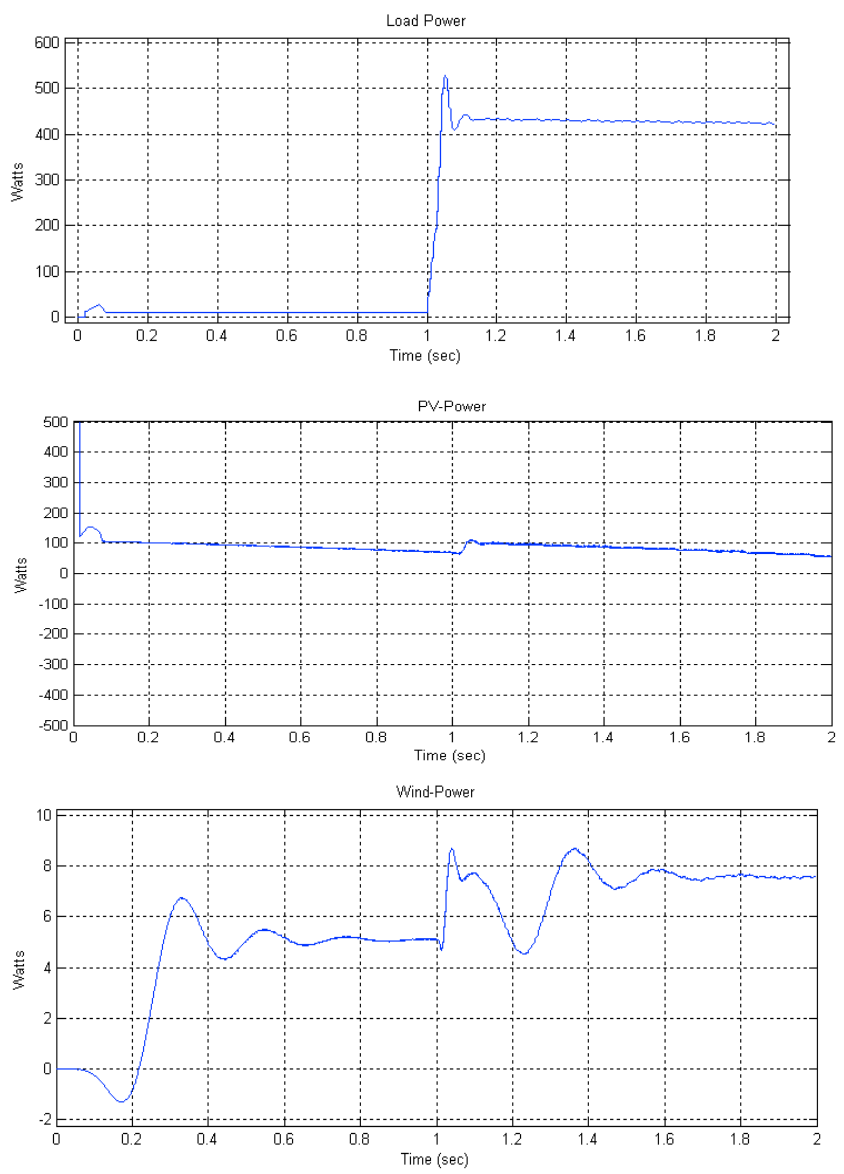

Fig.9.Power of load, Solar and Wind

From $\mathrm{t}=0$ to $1 \mathrm{load}$ is set to $20 \mathrm{ohms}$, corresponding generated power $(\mathrm{PV}+$ Wind $)$ is 105 watts and from $\mathrm{t}=1$ to 2 load is set to $1 \mathrm{ohms}$, corresponding generated power ( PV + Wind) 108watts
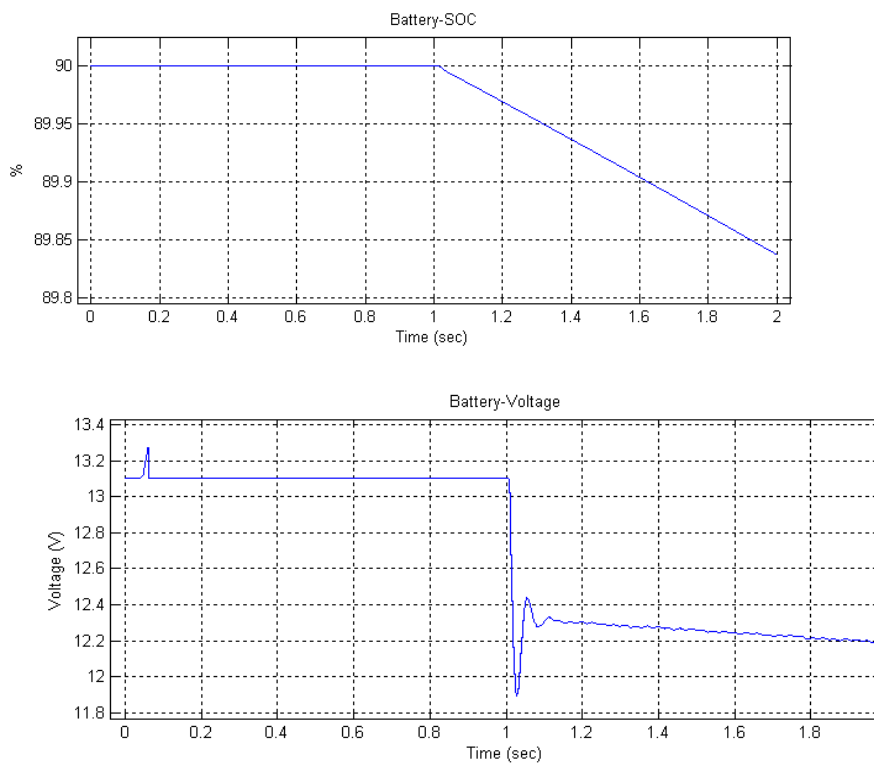

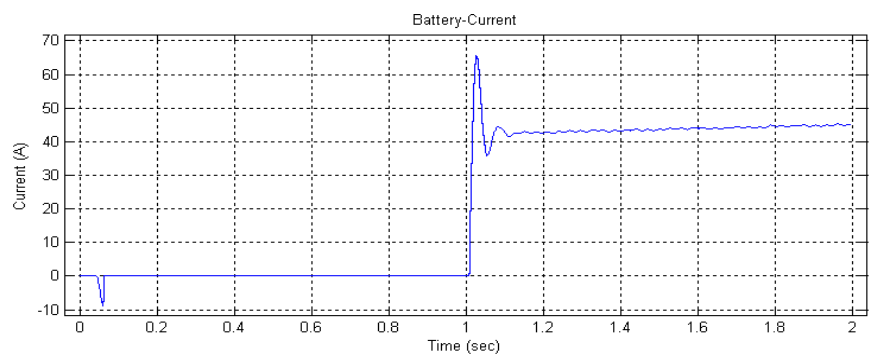

Fig.10. Battery SOC, Current and Voltage

Hence From $\mathrm{t}=0$ to 1 load power $<$ generated power so battery will charge and from $\mathrm{t}=1$ to 2 load power $>$ generated ppower so battery will discharge
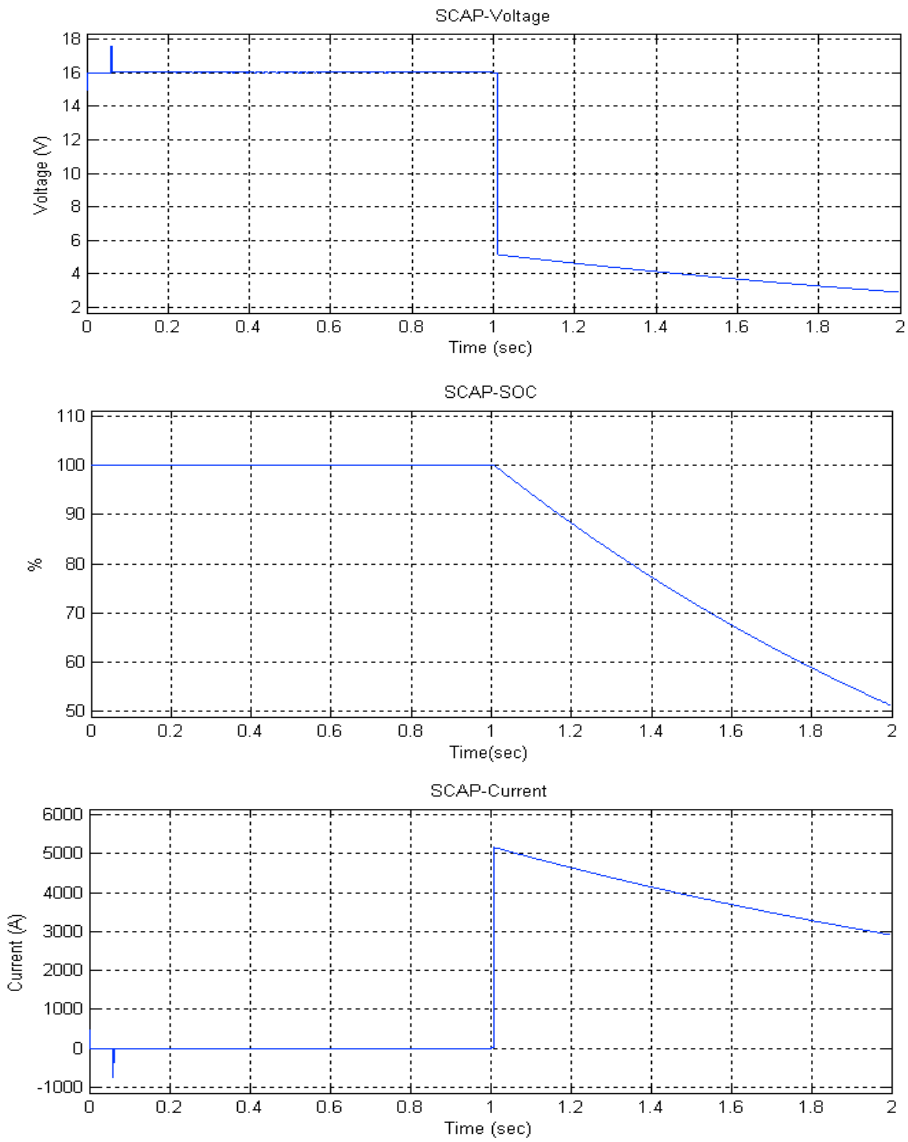

Fig.11. Super capacitor SOC, Current and Voltage

Hence From $\mathrm{t}=0$ to 1 load power $<$ generated power so SCAP will charge and from $\mathrm{t}=1$ to 2 load power $>$ generated power so SCAP will discharge

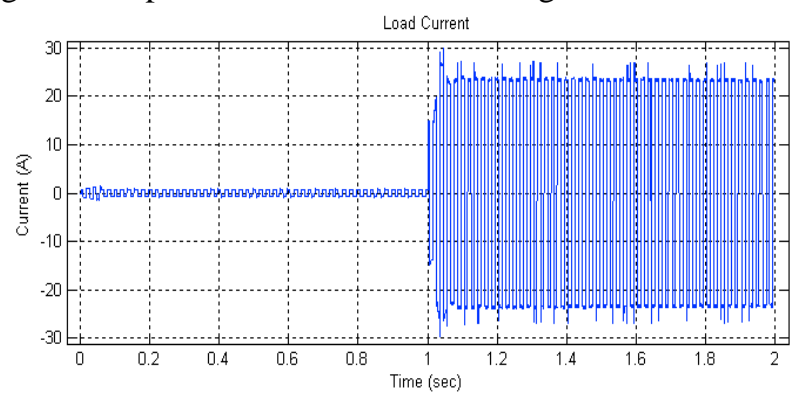

Published By: 

SMALL SCALE MICRO GRID WITH HYBRID STORAGE SYSTEM

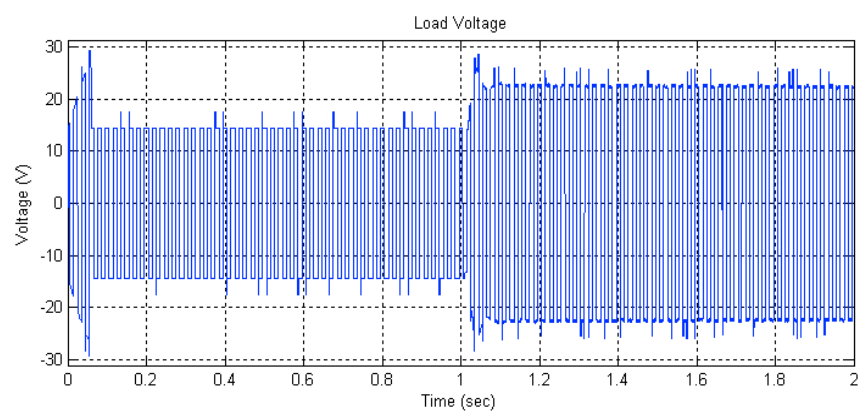

Fig.12. Load, Current and Voltage
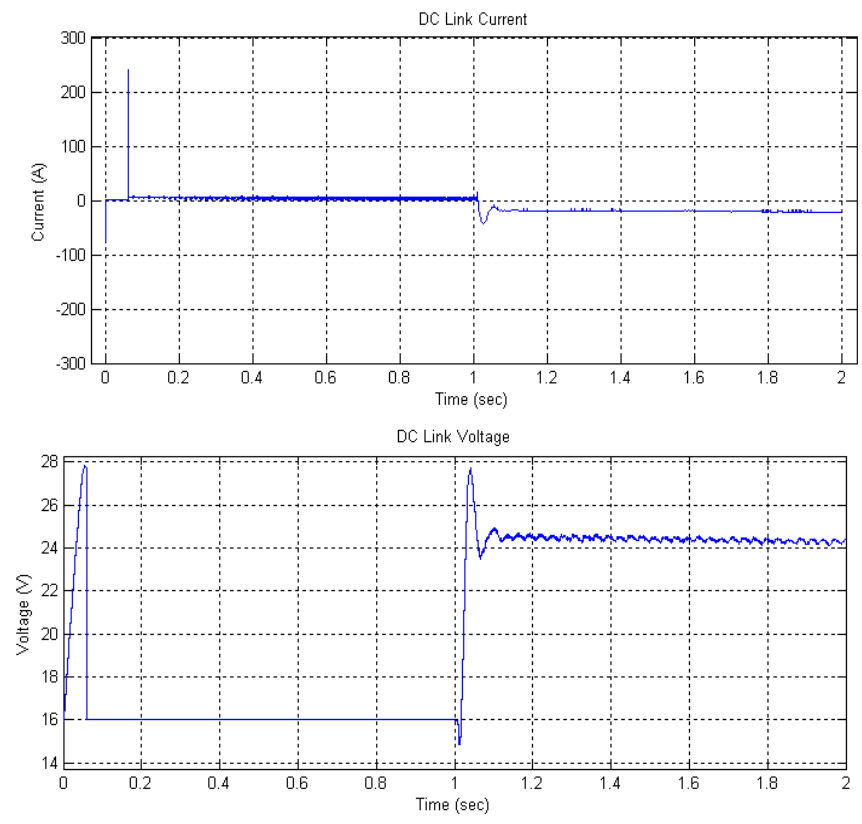

Fig.13. DC link Current and Voltage

\begin{tabular}{|l|lr|l|l|}
\hline \multirow{2}{*}{ S.No } & \multirow{2}{*}{ Parameter } & \multicolumn{2}{|c|}{ Values } \\
\cline { 3 - 4 } & & Charging & Discharging \\
\hline 1 & Battery output & $13.1 \mathrm{~V}$ & $12.2 \mathrm{~V}$ \\
\hline 2 & Battery output & $1 \mathrm{~A}$ & $45 \mathrm{~A}$ \\
\hline 3 & Battery SOC & 90 & 85 \\
\hline 4 & SCAP output voltage & 16 & 5 \\
\hline 5 & SCAP output Current & $1 \mathrm{~A}$ & $3000 \mathrm{~A}$ \\
\hline 6 & SCAP SOC & 100 & 50 \\
\hline
\end{tabular}

Table .1 System Specification for DC/DC Converter

\section{CONCLUSION}

The work represented a bidirectional converter of DcDc for Small scale Micro grid, with the possibility of Hybrid state harge bank power exchange topology. Control calculations and Power converters are produced to give control similarity and energy management between various assets in the micro grid. The plot of super capacitor. Utilizing that readings, the plot of control detaches the super capacitor and battery from the converter however much as could reasonably be expected to lessen the working time of battery and super capacitor therefore its life. control indicates a most and least range for Battery and

\section{REFERENCES}

1. Masanori Ishigaki, Member, IEEE, Jongwon Shin, Member, IEEE and Ercan M. Dede, Member, IEEE " $A$ Novel Soft Switching Bidirectional DC-DC Converter Using Magnetic and Capacitive Hybrid Power Transfer", IEEE transactions on power electronics, DOI 10.1109/tpel.2016.2624024, IEEE

2. Hamed Babazadeh, Wenzhong Gao, Xiaoyu Wang "Controller Design for a Hybrid Energy StorageSystem Enabling Longer Battery Life in WindTurbine Generators" This work was supported in part by Department of Energy Grant DE-EE0001383,2016

3. X.Y. Wang, Don Mahinda, Vilath Gamuwa and S.S. Choi,"Determination of Battery Storage Capacity in Energy Buffer for Wind Far", IEEE Transactions on Energy Conversion, Vol. 23, NO. 3, September 2018, p. 868-879.

4. W. Saad and A. Jaekel ,A. Bari, J. Jiang, "Challenges in the Smart Grid Applications: An Overview," Int. J. of Distributed Sensor Networks" international journals of Distributed sensor network",pp.1-12, 2014. https://DoI.org/10.1155/2014/974682

5. M. B. Shadmand and R. S. Balog, "Multi-objective optimization and design of photovoltaic-wind hybrid system for community smart DC microgrid," IEEE Trans. Smart Grid, DoI: 10.1109/TSG.2014.2315043vol. 5, no. 5, pp. 2635-2643, Sep.2014.

6. M. A. Mahmud and M. Aldeen ,M. J. Hossain, H. R. Pota, , "Robust control for power Sharing in microgrids with lowinertia wind and PV generators," IEEE Trans. Sustain. Energy, vol. 6, no. 3, pp. 1067-1077, Jul. 2015. Doi: $10.1109 /$ TSTE.2014.2317801

7. Takafumi Akagi, Seiya Abe and "Renewable An Isolated DC-DC Converter Using Air-core Inductor For Power Supply on Chip Applications," Energy Reports,. DOI: 10.1109/COMPEL.2016.7556774Conference: 2016 IEEE 17th Workshop on Control and Modeling for Power Electronics (COMPEL)

8. Junming Zhang, Senior Member, IEEE, Zhaohui Wang, Shuai Shao, "A Three Phase Modular Multilevel DC-DC Converter for Power Electronic Transformer Applications," JOURNAL OF EMERGING AND SELECTED TOPICS IN POWER ELECTRONICS, 21686777 (c) 2016 IEEE

9. Dmitri Vinnikov, Senior Member, IEEE, Andrii Chub, Student Member, "High-Performance Quasi-Z-Source Series Resonant DC-DC Converter for Photovoltaic Module Level Power Electronics Applications.,DOI 0.1109/TPEL.2016.2591726, IEEE Transactions on Power Electronics

10. X. Lai, X. Li, D. Hui, and "Battery energy storage station (BESS)based smoothing control of photovoltaic $(P V)$ and wind power generation fluctuations," IEEE Trans. Sustain. Energy, vol. 4, no. 2, pp.464-473, 2013. Doi: $10.1109 /$ TSTE.2013.2247428

11. A. Kwasinski, S. Bae, and "Dynamic modeling and operation strategy for a microgrid with wind and photovoltaic resources," IEEE Trans.Smart Grid, vol. 3, no. 4, pp. 1867-1876, 2012. Doi: 10.1109/TSG.2012.2198498

12. Yu Chen1, Shanshan Zhao1, Zuoyu Li1, Xiaoguang Wei2 and Yong Kang1 "Modeling and Control of the Isolated DC-DC ModularMultilevel Converter for Electric Ship Medium Voltage Direct Current (MVDC) Power System," IEEE Trans. Smart Grid, DOI 
10.1109/JESTPE.2016.2615071, IEEE Journalof Emerging and Selected Topics in Power Electronics

13. O. A. Mohammed ,M. Farhadi,, "Design and hardware implementation of laboratory-scale hybrid DC power system for educational purpose," in Proc.122 ASEE Annual Conference and Exposition, Seattle,Washington, USA, 2015.

14. Chad Abbey and Geza Joos, "Supercapacitor Energy Storage for Wind Energy Applications", IEEE Transactions on Industry Applications" Doi: 10.1109/TIA.2007.895768, Vol.43, NO. 3, May/June 2007, p. 769-777.

15. Leandro Roggia, Luciano Schuch, Jos'e Eduardo Baggio, Cassiano Rech, Member, IEEEand Jos'e Renes Pinheiro, Member, IEEE "Integrated Full-Bridge-Forward DC-DC Converter for a Residential Microgrid Application" IEEE transactions on power electronics, Doi: 10.1109/TPEL.2012.2214061 vol. 28, no. 4, april 2013

16. Biao Zhao, Student Member, IEEE, Qingguang Yu, Member, IEEE, and Weixin Sun" Extended-Phase-Shift Control of Isolated Bidirectional DC-DC Converter for Power Distribution in Microgrid" IEEE transactions on power electronics, Doi: 10.1109/TPEL.2011.2180928 vol. 27, no. 11, november 2012 